\title{
SENSORINEURAL DEAFNESS IN MUCOSAL TYPE OF CHRONIC OTITIS MEDIA OF ADULTS
}

\author{
Suchit Roy B. R1, Salima Rema Windsor², Namitha V. Krishna ${ }^{3}$ \\ ${ }^{1}$ Additional Professor, Department of ENT, Government Medical College, Kollam. \\ ${ }^{2}$ Assistant Professor, Department of ENT, Government Medical College, Thiruvananthapuram. \\ ${ }^{3}$ Consultant ENT Surgeon, Department of ENT Surgeon, KIMS Hospital, Kottayam.
}

\section{ABSTRACT}

\section{BACKGROUND}

Chronic Suppurative Otitis media (CSOM) is a chronic inflammation of the mucosa of the middle ear cleft with variable involvement of its bony walls depending on the virulence of the organism and recurrent attacks. Absorption of the bacterial toxins through the round window during the process of infection and repeated usage of local antibiotics in the form of ear drops results in sensorineural deafness.

\section{MATERIALS AND METHODS}

50 patients with CSOM Sensorineural deafness were taken as a study group and 108 patients with CSOM without Sensorineural hearing loss as a control group were included in the study. Pure tone audiometry using narrow band masking for all patients of study and control groups were analysed on the basis of duration of disease, site of perforation, size of perforation and the pattern of middle ear mucosa. The pattern of hearing loss (Sensorineural element) in terms of degree and mostly involved frequencies was also studied.

\section{RESULTS}

The age groups of 20 to 29 and 30 to 39 were involved in both the groups. There was no predilection to the sex of the patients. The duration of the disease showed a significant correlation between increasing duration and SNHL ( $p$ value of 0.001 ). The study group patients showed (49.1\%) higher frequency involvement mostly (2000 and $4000 \mathrm{~Hz}$ ) unlike the control group.

\section{CONCLUSION}

A significant correlation between sensorineural hearing loss and increased age of the patient in chronic suppurative otitis media was observed from this study ( $>40$ years). Definite and significant correlation was observed between sensorineural hearing loss and increased duration of chronic suppurative otitis media. ( $>10$ years). No significant correlation was found between sensorineural hearing loss and factors like otorrhoea status, site and size of tympanic membrane perforation or status of middle ear mucosa. Mild-to-moderate degree of sensorineural hearing loss among cases was observed, with mild degree predominating. Higher frequencies (2000 and $4000 \mathrm{~Hz}$ ) were involved by the sensorineural element.

\section{KEYWORDS}

CSOM, Toxins, Sensorineural Hearing Loss, Hearing, Virulence.

HOW TO CITE THIS ARTICLE: Roy SBR, Windsor SR, Krishna NV. Sensorineural deafness in mucosal type of chronic otitis media of adults. J. Evolution Med. Dent. Sci. 2017;6(5):408-412, DOI: 10.14260/Jemds/2017/91

\section{BACKGROUND}

Chronic suppurative otitis media is the result of an initial episode of acute otitis media and is characterised by a persistent discharge from the middle ear. It is a major public health problem and an important cause of preventable hearing loss particularly in the developing world. Prevalence surveys, which vary widely in disease definition, sampling methods, and methodological quality, show that the global burden of illness from chronic suppurative otitis media involves 65 -330 million individuals with draining ears, 60\% of whom (39-200 million) suffer from significant hearing impairment. ${ }^{1} \mathrm{~A}$ true estimate of the problem of deafness is not known in India. ${ }^{2}$ Chronic Suppurative otitis

Financial or Other, Competing Interest: None.

Submission 08-12-2016, Peer Review 02-01-2017,

Acceptance 07-01-2017, Published 16-01-2017.

Corresponding Author:

Dr. Suchit Roy B. R,

Additional Professor,

Department of ENT,

Government Medical College, Kozhikode.

E-mail: suchitroybr@hotmail.com

DOI: $10.14260 /$ jemds $/ 2017 / 91$ media accounts for 28,000 deaths and a disease burden of over two million disability-adjusted life-years (DALYs). Over $90 \%$ of the burden is borne by countries in the South-east Asia and Western Pacific regions, Africa, and several ethnic minorities in the Pacific ring. ${ }^{1}$ Patients may present with a discharging ear, hearing loss and/or with headache, fever, dizziness, and other danger signs. Diagnosis is by history \& otoscopy. Pure tone audiometry and Tympanometry are important in assessing the degree and type of hearing loss. It occupies a considerable amount of clinic and operating time of Otolaryngologist. But the role of chronic otitis media as a cause of sensorineural hearing loss is still debatable. However, several investigators have reported that loss of cochlear function does occur as a common sequel of chronic suppurative otitis media. ${ }^{1}$ A permanent abnormality of the pars tensa or flaccida, most likely a result of earlier acute otitis media, negative middle ear pressure or otitis media with effusion also implies the diagnosis. ${ }^{3,4}$ The disease usually begins in childhood 5,6 as a spontaneous tympanic membrane perforation due to an acute infection of the middle ear, known as acute otitis media or as a sequel of less severe forms of otitis media (e.g. secretory). ${ }^{7}$ Generally, patients with tympanic perforations which continue to discharge 
mucoid material for periods of from 6 weeks ${ }^{8}$ to 3 months, despite medical treatment, are recognised as cases of chronic suppurative otitis media. The WHO definition requires only 2 weeks $^{9}$ of otorrhoea, but otolaryngologists tend to adopt a longer duration, e.g. more than 3 months ${ }^{10}$ of active disease. Chronic suppurative otitis media can be further sub-classified into those cases with or without aural cholesteatoma. Cholesteatomas are epidermal inclusion cysts within the pneumatised portions of the temporal bone. Cholesteatoma can be classified as either congenital or acquired with the later variant being further divided into primary or secondary forms.11,12 The present study is a prospective study on patients with chronic Suppurative otitis media-tubotympanic type, attending the OPD of Department of Otorhinolaryngology, Government Medical College, Thiruvananthapuram, between January 2011 and January 2012.

\section{Aim and Objectives}

To study the determinants or associations of sensorineural hearing loss in chronic suppurative otitis mediatubotympanic type among adults.

\section{Objectives}

1. To study the determinants or associations of sensorineural hearing loss in chronic suppurative otitis media- tubotympanic type among adults.

2. To study the pattern of sensorineural hearing loss among cases.

\section{MATERIALS AND METHODS}

This is an observational-case control study of patients with chronic suppurative otitis media-tubotympanic disease, who had attended the Outpatient Department of Otorhinolaryngology, Government Medical College, and Thiruvananthapuram. The period of study was between January 2011 and January 2012.

\section{Inclusion Criteria}

The study population consisted of patients as above mentioned with an age limit of 12-45 years of age excluding those as per the exclusion criteria.

\section{Exclusion Criteria}

Patients with History of a. Habitual exposure to noise, b. Head injury, c. Previous ear surgery, d. Frank labyrinthitis, e. Familial hearing loss, f. Meningitis, g. Systemic diseases affecting hearing were not included. Patients with positive fistula test (55 in number) were defined as those patients with sensorineural hearing loss as investigated by pure tone audiometry among the diagnosed patients of chronic suppurative otitis media-tubotympanic type. Control group of patients (108 in number) were defined as physician diagnosed cases of chronic suppurative otitis media- tubotympanic type without sensorineural hearing. Hence, two types of controls were included; subjects with unilateral or bilateral chronic suppurative otitis media-tubotympanic type without sensorineural hearing loss. Subjects with bilateral chronic suppurative otitis media tubotympanic type without sensorineural hearing loss on one side. After getting informed consent, each patient was included in the study according to inclusion criteria. Each patient was evaluated according to the Proforma of the study. They were assessed primarily by their complaints and underwent complete clinical examination including otoscopic examination and tuning fork tests. Pure tone audiometry by a calibrated audiometer in a sound proof room was performed using narrow band masking for all cases and controls and were analysed based on duration of disease, site of perforation, size of perforation and the pattern of middle ear mucosa. Perforation was central which was further divided into small if only one quadrant of TM was involved, medium if two quadrants are involved, large if three or more quadrants are involved and subtotal if only thin rim of pars tensa is surrounding. The pattern of hearing loss (Sensorineural element) in terms of degree and mostly involved frequencies was also studied among cases. The results of this study were analysed statistically and conclusions made according to this. Statistical analysis was done using chi square and MannWhitney U tests (SPSS 11.0 version).

\section{RESULTS}

Among the study group patients (55), the most common age group involved were 20- 29 years and 30-39 years, both accounting to $36.4 \%$ (20 each). In the control group patients (108), the most common age group involved was 20 -39 years at $34.3 \%$ (37), followed by $30-39$ age group at $33.3(36 \%)$ among controls. Among study group, 12 (21.8\%) were in the $>40$ age group, while only $11(11.1 \%)$ patients among controls were included in this age group. Thus, a significant correlation was obtained between increasing age of the patients and sensorineural hearing loss ( $\mathrm{p}$ value 0.033 with $\mathrm{p}$ taken as significant at $<0.05$ ), (Table 1 ).

\begin{tabular}{|c|c|c|c|c|c|c|}
\hline \multirow{2}{*}{ Age } & \multicolumn{2}{|c|}{ Study Group } & \multicolumn{2}{|c|}{ Control Group } & \multirow{2}{*}{$\chi^{2}$} & \multirow{2}{*}{ P } \\
\cline { 2 - 5 } & Count & Percent & Count & Percent & & \\
\hline $10-19$ & 3 & 5.5 & 23 & 21.3 & & \\
\hline $20-29$ & 20 & 36.4 & 37 & 34.3 & & \\
\hline $30-39$ & 20 & 36.4 & 36 & 33.3 & \multirow{2}{*}{8.71} & \multirow{2}{*}{0.033} \\
\hline$>=40$ & 12 & 21.8 & 12 & 11.1 & & \\
\hline Total & $\mathbf{5 5}$ & & $\mathbf{1 0 8}$ & & & \\
\hline Mean \pm SD & $31.3 \pm 7.5$ & \multicolumn{2}{|c|}{$27.8 \pm 8.3$} & & \\
\hline \multicolumn{7}{|c|}{ Table 1. Showing the Incidence of HL in } \\
Study and Control Groups (n=50 \& 108) \\
\hline
\end{tabular}

Among the study group patients, 29 (52.7\%) were male and $26(47.3 \%)$ were female. The number of males and females were 54 each (50\%) among control group. The p values were not significant ( $p$ at 0.742 ) (Table 2).

\begin{tabular}{|c|c|c|c|c|c|c|}
\hline \multirow{2}{*}{ Sex } & \multicolumn{2}{|c|}{ Study Group } & \multicolumn{2}{|c|}{ Control Group } & \multirow{2}{*}{$\chi^{2}$} & \multirow{2}{*}{} \\
\cline { 2 - 5 } & Count & Percent & Count & Percent & & \\
\hline Male & 29 & 52.7 & 54 & 50.0 & & \\
\hline Female & 26 & 47.3 & 54 & 50.0 & 0.11 & 0.742 \\
\hline Total & $\mathbf{5 5}$ & $\mathbf{1 0 0}$ & $\mathbf{1 0 8}$ & $\mathbf{1 0 0}$ & & \\
\hline & Table 2. Showing the Gender Incidence among \\
the Study and Control Groups (n=50 \& 108) \\
\hline
\end{tabular}

Comparison of diseased ear showed left ear involvement in (21) 38.2\% among patients of study group and (45) $41.7 \%$ among control group patients. While the right ear involvement was $58.2 \%$ (32) and $41.7 \%$ (45) respectively among study and controls. Both ears were involved in $3.6 \%$ (2) of cases and $16.7 \%$ (18) of controls (Table 3). 


\begin{tabular}{|c|c|c|c|c|}
\hline \multirow{2}{*}{$\begin{array}{c}\text { Diseased } \\
\text { Ear }\end{array}$} & \multicolumn{2}{|c|}{ Study Group } & \multicolumn{2}{c|}{ Control Group } \\
\cline { 2 - 5 } & Count & Percent & Count & Percent \\
\hline Left & 21 & 38.2 & 45 & 41.7 \\
\hline Right & 32 & 58.2 & 45 & 41.7 \\
\hline Both & 2 & 3.6 & 18 & 16.7 \\
\hline Total & 55 & 100 & 108 & 100 \\
\hline \multicolumn{3}{|c|}{} \\
Table 3. Showing the Side of Involvement in \\
Study and Control Groups (n=50 \& $n=108)$ \\
\hline
\end{tabular}

The duration of disease was compared between the study group patients and control group patients and a significant correlation between increasing duration and SNHL was observed ( $p$ value of 0.001 ). 12 among study group (21.1\%) had disease duration of $>10$ years and 14 among control group (11.1\%) showed such a longer duration (Table 4).

\begin{tabular}{|c|c|c|c|c|c|c|}
\hline Duration & Study Group & Control Group & $\chi \mathbf{2}$ & $\mathbf{p}$ \\
\hline & Count & Percent & Count & Percent & & \\
\hline $1-5$ & 3 & 5.3 & 35 & 27.8 & & \\
\hline $6-10$ & 42 & 73.7 & 77 & 61.1 & & \\
\hline$>10$ & 12 & 21.1 & 14 & 11.1 & 13.26 & 0.001 \\
\hline Total & $\mathbf{5 7}$ & & $\mathbf{1 2 6}$ & & & \\
\hline Mean \pm SD & $8.7 \pm 2.6$ & \multicolumn{3}{|c|}{$7.2 \pm 3.7$} & & \\
\hline \multicolumn{6}{|c|}{ Table 4. Comparison of Sample } \\
Based on Duration (n=50 \& $\mathbf{n = 1 0 8 )}$ \\
\hline
\end{tabular}

Otorrhoea was defined as the presence of ear discharge at the time of diagnosis. Among the study group patients, 31 (54.4\%) had dry ears and $26(45.6 \%)$ had wet ears, while the number in control group was 75 (59.5\%) and 51 (40.5\%) respectively. There was no statistically significant relation between sensorineural hearing loss and state of otorrhoea (Table 5).

\begin{tabular}{|c|c|c|c|c|c|c|}
\hline Otorrhoea & Study Group & \multicolumn{2}{|c|}{ Control Group } & \multirow{2}{*}{$\chi^{2}$} & \multirow{2}{*}{ p } \\
\cline { 1 - 5 } Status & Count & Percent & Count & Percent & & \\
\hline Dry & 31 & 54.4 & 75 & 59.5 & & \\
\hline Wet & 26 & 45.6 & 51 & 40.5 & 0.43 & 0.514 \\
\hline Total & $\mathbf{5 7}$ & $\mathbf{1 0 0}$ & $\mathbf{1 2 6}$ & $\mathbf{1 0 0}$ & & \\
\hline \multicolumn{7}{|c|}{ Table 5. Comparison of Samples based } \\
on Otorrhoea Status (n=50 \& $\mathbf{n = 1 0 8 )}$ \\
\hline
\end{tabular}

No significant correlation was observed between sensorineural hearing loss and the site of perforation. Comparison of cases and controls in terms of involvement of posterior half of tympanic membrane showed no significant relation between SNHL and site of perforation (Table 6).

\begin{tabular}{|c|c|c|c|c|c|c|}
\hline $\begin{array}{c}\text { Site of } \\
\text { Perforation }\end{array}$ & \multicolumn{2}{|c|}{ Study Group } & \multicolumn{2}{|c|}{ Control Group } & $\chi^{\mathbf{2}}$ & $\mathbf{p}$ \\
\cline { 2 - 7 } & Number & $\%$ & Number & $\%$ & & \\
\hline PS + PI & 36 & 63.2 & 96 & 76.2 & & \\
\hline Others & 21 & 36.8 & 30 & 23.8 & 3.32 & 0.069 \\
\hline Total & 57 & 100 & 126 & 100 & & \\
\hline \multicolumn{7}{|c|}{ Table 6. Showing the Correlation between } \\
the site of Perforation and the \\
Sensorineural Hearing Loss (n=50 \& $\boldsymbol{n = 1 0 8 )}$ \\
\hline
\end{tabular}

No significant relation was observed between sensorineural hearing loss and size of perforation. Here, analysis was done using Mann Whitney U test instead of Chi square test (Table 7).

\begin{tabular}{|c|c|c|c|c|c|c|}
\hline \multirow{2}{*}{$\begin{array}{c}\text { Size of } \\
\text { Perforation }\end{array}$} & \multicolumn{2}{|c|}{ Case } & \multicolumn{2}{|c|}{ Control } & \multirow{2}{*}{$\chi^{2}$} & \multirow{2}{*}{$\mathbf{P}$} \\
\hline & Count & \begin{tabular}{|l|} 
Percent \\
\end{tabular} & Count & Percent & & \\
\hline ST & 3 & 5.3 & 15 & 11.9 & & \\
\hline Large & 29 & 50.9 & 48 & 38.1 & & \\
\hline Medium & 25 & 43.9 & 37 & 29.4 & 1.28 & 0.200 \\
\hline Small & 0 & 0.0 & 26 & 20.6 & & \\
\hline Total & 57 & 100 & 126 & 100 & & \\
\hline $\begin{array}{r}\text { Tal } \\
\text { onth }\end{array}$ & $\begin{array}{l}\text { e 7. Co } \\
\text { Size o }\end{array}$ & $\begin{array}{l}\text { mparison } \\
\text { fPerforat }\end{array}$ & $\begin{array}{l}\text { of Sal } \\
\text { on }(n\end{array}$ & $\begin{array}{l}\text { ples ba } \\
0 \text { \& } n=\end{array}$ & & \\
\hline
\end{tabular}

No significant correlation was observed between SNHL and status of middle ear mucosa (Table 8).

\begin{tabular}{|c|c|c|c|c|c|c|}
\hline \multirow{2}{*}{ Mucosa } & \multicolumn{2}{|c|}{ Study Group } & \multicolumn{2}{|c|}{ Control Group } & \multirow{2}{*}{$\chi^{2}$} & \multirow{2}{*}{$\mathbf{p}$} \\
\hline & Count & $\%$ & Count & $\%$ & & \\
\hline Pale & 29 & 50.9 & 68 & 54.0 & \multirow{4}{*}{0.39} & \multirow{4}{*}{0.825} \\
\hline Polypoidal & 26 & 45.6 & 52 & 41.3 & & \\
\hline $\begin{array}{l}\text { Tympano- } \\
\text { sclerosis }\end{array}$ & 2 & 3.5 & 6 & 4.8 & & \\
\hline Total & 57 & 100 & 126 & 100 & & \\
\hline $\begin{array}{c}\text { Table } 8 \\
\text { on Statt }\end{array}$ & $\begin{array}{l}\text { owin } \\
\text { fthe }\end{array}$ & $e C$ & pariso & Sam & & $\begin{array}{l}\text { ed } \\
08)\end{array}$ \\
\hline
\end{tabular}

Among cases, 32 (56.1\%) had mild degree of SNHL and 25 (43.9\%) had moderate degree of sensorineural hearing loss (Table 9).

\begin{tabular}{|c|c|c|}
\hline Degree & Count & Percent \\
\hline Mild & 32 & 56.1 \\
\hline Moderate & 25 & 43.9 \\
\hline Total & $\mathbf{5 7}$ & $\mathbf{1 0 0}$ \\
\hline \multicolumn{2}{|c|}{ Table 9. Showing the Percentage Distribution } \\
of the Sample, According to Degree of \\
Sensorineural Hearing Loss (n=50 \&n=108) \\
\hline
\end{tabular}

When the frequency of involvement by the sensorineural element was analysed in cases, in terms of increased bone conduction thresholds, 28 patients $(49.1 \%)$ had high frequency involvement mostly in 2000 and $4000 \mathrm{~Hz}$ (Table 10).

\begin{tabular}{|c|c|c|}
\hline Frequency & Number & Percent \\
\hline $1000 \mathrm{KHz}$ & 1 & 1.8 \\
\hline $2000 \mathrm{KHz}$ & 11 & 19.3 \\
\hline $1000,2000 \mathrm{KHz}$ & 1 & 1.8 \\
\hline $1000,2000,4000 \mathrm{KHz}$ & 16 & 28.1 \\
\hline $2000,4000 \mathrm{KHz}$ & 28 & 49.1 \\
\hline Total & 57 & 100 \\
\hline \multicolumn{3}{|c|}{$\begin{array}{l}\text { Table 10. Showing the Frequencies of Hearing } \\
\text { Loss in Group A Study Group Patients }(n=50)\end{array}$} \\
\hline
\end{tabular}

\section{DISCUSSION}

This study included 55 patients as cases and 108 patients as controls, who attended the outpatient clinic of Department of Otorhinolaryngology, Medical College, and Thiruvananthapuram during the study period (January 2011 to January 2012). In the present study, associations of sensorineural hearing loss among cases were compared with 
those among controls. Most of the studies in literature were conducted among patients with unilateral chronic suppurative otitis media who had normal hearing in the contralateral ear so that the contralateral ear served as the control. All among cases showed mixed hearing loss in this study. Comparison based on age showed significant correlation between sensorineural hearing loss and increasing age with a ' $p$ ' value of 0.033 . This observation coincides with the studies done by de Azevedo AF et al (2007) ${ }^{13}$ and Feng $\mathrm{H}$ et al (2004). ${ }^{14}$ In the present study, most of the patients were included in the age range of 20-39 years, both among cases and controls. $21.8 \%$ among cases were in the above 40 years age group, while only $11.1 \%$ among controls were included in this age group. A significant correlation between duration of the disease and SNHL was observed from this study. The ' $p$ ' value was 0.001 . The disease duration was $>10$ years in $21.1 \%$ of cases and $11.1 \%$ of controls. This result is in agreement with that of Paparella et al (1970), ${ }^{15}$ English et al (1973), ${ }^{16}$ Dumich (1983), ${ }^{17}$ Cusimano et al (1989), 18 K.K Handa et al (1996), ${ }^{19}$ Kholmatov (2001) ${ }^{20}$ and Sharma Karan et al (2005). ${ }^{21}$ In a study done by Neeraj Kasliwal, Sanjeev Joshi and S. M. Pareek among 510 cases of unilateral CSOM, duration of disease had a significant association with SNHL ( $>15$ years duration, 'p' value for $1000 \mathrm{~Hz}$ frequency was 0.006).2 Another study conducted by Kamaljith Kaur, Nishi Sonkhya and A.S Bapna among 100 cases of unilateral CSOM, a progressively increasing incidence of SNHL was found as the duration of disease increased. The incidence of SNHL was found to be $13.64 \%$ when the duration of disease was $<5$ years and progressively rose to $33.33 \%$ when the duration was $>26$ years. ${ }^{22}$ No significant correlation was found between duration of the disease and SNHL according to Noordzig et al (1995) ${ }^{23}$ and MacAndie et al (1999). ${ }^{24}$ This study analysed the pattern of sensorineural element of hearing loss among cases, which showed a preferential involvement of higher frequencies (At 2000 and $4000 \mathrm{~Hz}$ in $49.1 \%$ among cases). Similar results are obtained in the studies conducted by Paparella et al (1972) ${ }^{25}$ and Lundman et al (1992). ${ }^{26}$ Fria et $\mathrm{al}^{27}$ found that there was a tendency for bone conduction thresholds to be elevated at 2 $\mathrm{KHz}$ and $4 \mathrm{KHz}$ in the ears with chronic otitis media. According to Neeraj Kasliwal et al, ${ }^{2}$ increase in bone conduction threshold was significant at frequencies $2 \mathrm{KHz}$ and $4 \mathrm{KHz}$ ('p' value of <0.001). Assessment of degree of hearing loss showed $56.1 \%$ having mild degree of SNHL. 43.9\% had moderate degree of SNHL among cases.

This data correlates with that of Paparella (1972), which showed sensorineural hearing loss of 19-33 dB across higher frequencies in ears with chronic infections. No significant association was observed between SNHL and factors like otorrhoea status, site or size of perforation, or status of middle ear mucosa in the present study. According to the study conducted by Neeraj Kasliwal et al, ${ }^{2}$ greater loss in bone conduction thresholds was seen in subtotal and attic perforations, especially at speech frequencies. The same study showed a significant correlation between severity of sensorineural hearing loss, presence of cholesteatoma and erosion of ossicular chain. But there was no statistically significant relation between SNHL and state of otorrhoea. No significant correlation was seen between sensorineural hearing loss and background characteristics of sample other than age (which include gender, side affected by the disease).
This result coincides with the observations of Neeraj Kasliwal et al where male to female ratio and the side of the ear affected was the same.

\section{CONCLUSION}

The following conclusions are made from this study. A significant correlation between sensorineural hearing loss and increased age of the patient in chronic suppurative otitis media was observed from this study ( $>40$ years). Definite and significant correlation was observed between sensorineural hearing loss and increased duration of chronic suppurative otitis media ( $>10$ years). No significant correlation was found between sensorineural hearing loss and factors like otorrhoea status, site and size of tympanic membrane perforation or status of middle ear mucosa. Mild-to-moderate degree of sensorineural hearing loss among cases was observed, with mild degree predominating. Higher frequencies (2000 and $4000 \mathrm{~Hz}$ ) were involved by the sensorineural element.

\section{Recommendations}

This study showed a significant correlation between sensorineural hearing loss and increasing duration of chronic suppurative otitis media, emphasising the fact that the disease should be diagnosed early, by increasing awareness amongst people and managed effectively so as to prevent the chances of developing sensorineural hearing loss as a sequel.

\section{Limitations}

The sample size of this study is small, comparing the global burden of chronic suppurative otitis media. If similar studies are conducted among larger samples the results may vary. Only tubotympanic variety of chronic suppurative otitis media was taken into consideration in the present study. Consideration of atticoantral variety may help to find other associations or determinants.

\section{REFERENCES}

[1] World Health Organization. Chronic suppurative otitis media, burden of illness and management options. Child and Adolescent Health and Development, Prevention of Blindness and Deafness, Geneva 2004.

[2] Kasliwal N, Joshi S, Pareek SM. Determinants of sensorineural hearing loss in chronic middle ear disease. Indian J of Otolaryngology and Head and Neck Surgery 2004;56(4):269-73.

[3] Levine SC, Souza CD. Intracranial complications of otitis media. $5^{\text {th }}$ edn. In: Glasscock ME, Gulya AJ, edtrs. Glasscock-Shambaugh Surgery of the ear. Hamilton, Ont: B.C. Decker 2003:443-61.

[4] Hamilton J. Chronic otitis media in childhood. Chapter 74. $7^{\text {th }}$ edn. Scott-Brown's otolaryngology, head and neck surgery. 2008:928-30.

[5] Jahn AF. Chronic otitis media: diagnosis and treatment. Med Clin North America 1991;75(6):1277-91.

[6] McPherson B, Holborow CA. A study of deafness in West Africa: the Gambian hearing health project. Int J Pediatr Otorhinolaryngol 1985;10(2):115-35.

[7] Tos M. Causes of the disease. Ann Otolaryngol-Head and Neck Surg 1990;4:146-7. 
[8] Kenna MA. Treatment of chronic suppurative otitis media. Otolaryngol Clin North America 1994;27(3):457-72.

[9] Smith AW, Hatcher J, Mackenzie IJ, et al. Randomised control of chronic suppurative otitis media in Kenyan school children. Lancet 1996;348(9035):1128-33.

[10] Goycoolea MV, Hueb MM, Ruah C. Definitions and terminology. Otolaryngol Clin North America 1991;24(4):757-61.

[11] Chole RA, Sudhoff HH. Chronic otitis media, mastoiditis and petrositis. Chapter 143. $4^{\text {th }}$ edn. Cummings C. Otolaryngology, Head and Neck Surgery. 2005:2989-3008.

[12] Chole RA, Nason R. Chronic otitis media and cholesteatoma. Vol $1.1^{\text {th }}$ edn. Ballenger's otorhinolaryngology, head and neck surgery. Chapter 17. 2009:1234-5.

[13] deAzevedo AF, Pinto DC, deSouza NJ, et al. Sensorineural hearing loss in chronic suppurative otitis media with and without cholesteatoma. Braz J Otorhinolaryngology 2007;73(5):671-4.

[14] Siampare L, Mann SBS, Panda NK, et al. Audiovestibular profile in unilateral chronic suppurative otitis media. Indian $\mathrm{J}$ of Otorhinolaryngology Head Neck Surg 1997;49(2):10711.

[15] Paparella MM, Brady DR, Hoel R. Sensorineural hearing loss in chronic otitis media and mastoiditis. Trans Am Acad Ophthalmol Otolaryngol 1970;74: 108-15.

[16] English GM, Northem JL, Fria TJ. Chronic otitis media as a cause of SNHL. Arch Otolaryngol 1973;98(1):1822.

[17] Dumich PS, Harner SG. Cochlear function in chronic otitis media. Laryngoscope 1983;93(5):583-6.
[18] Cusimano F, Cocita VC, D' Amico A. Sensorineural hearing loss in chronic otitis media. J Laryngol Otol 1989;103(2):158-63.

[19] Handa KK, Mann SBS, Gupta AK, et al. Sensorineural loss in unsafe chronic suppurative otitis media in paediatric age group. Indian J of Otorhinolaryngology and Head \& Neck Surgery 1996;48(2):125-9.

[20] Kholmatov DI. Early detection of a sensorineural aspect of hypoacusis in patients with chronic purulent otitis media. Vestn Otolaryngol 2001;3:26-8.

[21] Karan S, Gulati SK, Rupinder K. Sensorineural hearing loss in chronic suppurative otitis media-safe type. Indian J of Otology 2005;11:22-6.

[22] Kaur K, Sonkhya N, Bapna AS. Chronic suppurative otitis media and sensorineural hearing loss: is there a correlation? Indian J of Otolaryngology and Head and Neck Surgery 2003;55(1):21-4.

[23] Noordzig JP, Dodson EE, Ruth RA, et al. Chronic otitis media and sensorineural hearing loss: is there a clinically significant relation? Am J Otol 1995;16(4):420-3.

[24] MacAndie C, O’Reilly BF. Sensorineural hearing loss in chronic otitis media. Clin Otolaryngol Allied Sci 1999;24(3):220-2.

[25] Paparella MM, Oda M, Hiraide F, et al. Pathology of SNHL in otitis media. Ann Otol Rhinol Laryngol 1972;81(5):632-47.

[26] Lundman L, Santi PA, Morizono T, et al. Inner ear damage and passage through round window membrane of pseudomonas aeruginosa exotoxin $\mathrm{A}$ in a chinchilla model. Ann Otol Rhinol Laryngol 1992;101(5):437-44.

[27] Fria TJ, Cantekin EI, Eichler JA. Hearing acuity of children with otitis media with effusion. Arch Otolaryngol 1985;111(1):10-6. 